\section{European \\ Neurology}

Eur Neurol 2006;56:261

DOI: $10.1159 / 000096678$
Received: August 2, 2006

Accepted: August 2, 2006

Published online: October 31, 2006

\title{
Neuroimage: Monomelic Amyotrophy
}

\author{
$\begin{array}{llll}\text { P.K. Sethi } & \text { D. Khandelwal } & \text { R. Thukral } & \text { N.K. Sethi } \\ & \text { b } & \text { J. Torgovnick } \\ & \end{array}$

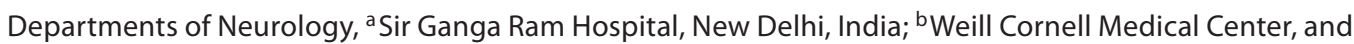 \\ 'Saint Vincent's Hospital and Medical Centers, New York, N.Y., USA
}

Dear Sir,

A 37-year-old lady presented to us for evaluation of a weakness of her right arm. She had first noticed an insidious onset of wasting of her right hand and forearm muscles at the age of 13 . This slowly progressed for 4-5 years and then stabilized without any medical intervention and she was able to perform all activities of daily living. There was no history of any sensory abnormality in that limb. Examination revealed atrophy of the flexor and extensor group of muscles of her right forearm and

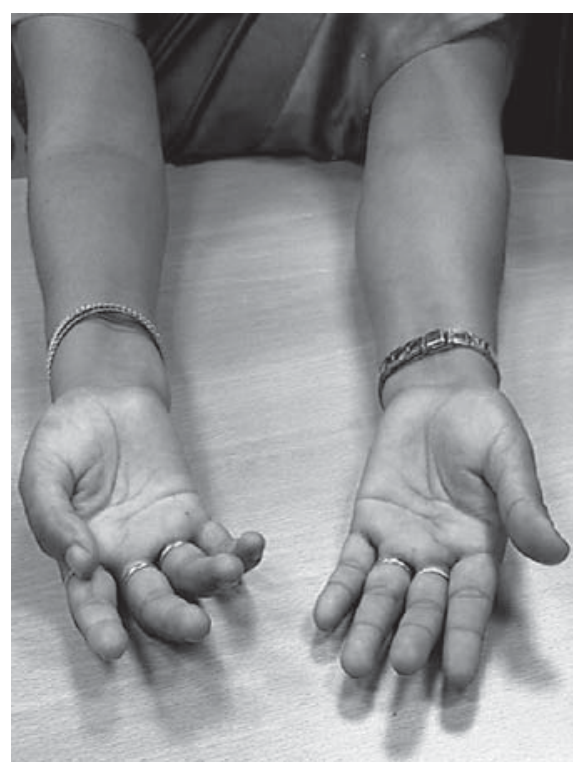

Fig. 1. Atrophy of the forearm and the intrinsic muscles of the right hand. of the intrinsic muscles of the hand (fig. 1). Deep tendon reflexes were normal and there was no sensory or motor deficits in other limbs tested. Electromyography showed evidence of diffuse renervation in the right arm. There was no evidence of a conduction block or sensory involvement.

Monomelic amyotrophy is a benign anterior horn cell disorder, clinically presenting as wasting of a single limb, first described by Hirayama in 1959 [1]. Magnetic resonance imaging of the cervical spine

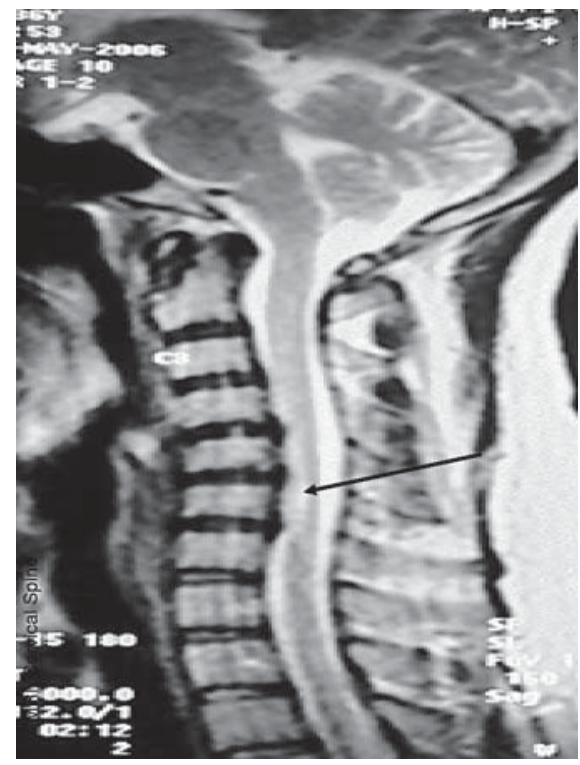

Fig. 2. $T_{2}$-weighted MRI of the cervical spine showing loss of the cervical spine curvature and a cord atrophy between C2 and C6. may reveal atrophy and increased signal intensity, which can be characteristic [2], as was seen in our case (fig. 2, 3).

\section{References}

1 Hirayama K, Toyokura Y, Tsubaki T: Juvenile muscular atrophy of upper extremity: a new clinical entity. Psychiatr Neurol Jap $1959 ; 61: 2190$

2 Pradhan S, Gupta RK: Magnetic resonance imaging in juvenile asymmetric segmental spinal muscular atrophy. J Neurol Sci 1997; 146:133-138.

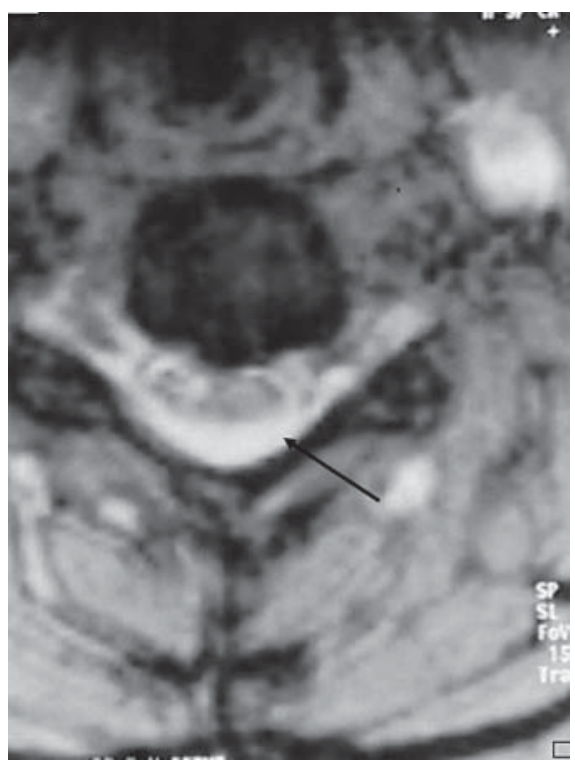

Fig. 3. Axial $\mathrm{T}_{2}$-weighted MRI of the cervical spine with a hyperintense signal on the right-hand side.

\section{KARGER}

Fax +41 613061234 E-Mail karger@karger.ch www.karger.com
Nitin Sethi, MD

Department of Neurology

Weill Cornell Medical Center

New York, NY 10021 (USA)

Tel. +1 646515 5168, E-Mail sethinitinmd@hotmail.com 